\title{
TGF- $\beta 1$ induces epigenetic silence of TIP30 to promote tumor metastasis in esophageal carcinoma
}

\author{
Fangfang $\mathrm{Bu}^{1,2,3, *}$, Xing Liu ${ }^{4,},{ }^{*}$ Jingjing $\mathrm{Li}^{1,}{ }^{*}$, Shukun Chen ${ }^{1}$, Xin Tong ${ }^{1,2,3}$, Chunsheng \\ $\mathrm{Ma}^{4}$, Hui Mao${ }^{1}$, Fei Pan ${ }^{1}$, Xiaoyan Li ${ }^{1,2}$, Bo Chen ${ }^{5}$, Liyan Xu ${ }^{5}$, Enmin $\mathrm{Li}^{5}$, Geng Kou ${ }^{1,2,6}$, \\ Jun Han', Shangjing Guo', Jian Zhao ${ }^{1,2,3}$ and Yajun Guo ${ }^{1,2,3,6}$ \\ ${ }^{1}$ PLA General Hospital Cancer Center Key Lab, Medical School of Chinese PLA, Beijing, P.R. China \\ ${ }^{2}$ International Joint Cancer Institute, The Second Military Medical University, Shanghai, P.R.China \\ ${ }^{3}$ Beijing Key Laboratory of Cell Engineering \& Antibody, Beijing, P.R. China \\ ${ }^{4}$ The 150 Hospital of Chinese PLA, Luoyang, P.R.China \\ ${ }^{5}$ Department of Biochemistry and Molecular Biology \& Institute of Oncologic Pathology, Shantou University Medical College, \\ Shantou, P.R.China \\ ${ }^{6}$ Department of Pharmacy, Liaocheng University, Liaocheng, P.R. China \\ * These authors contributed equally to this work \\ Correspondence to: Yajun Guo, email: yguo_smmu@163.com \\ Jian Zhao, email: zhaojian@smmu.edu.cn \\ Keywords: TIP30, TGF- $\beta 1$, methylation, epithelial-mesenchymal transition, ESCC \\ Received: October 22, $2014 \quad$ Accepted: December 02, $2014 \quad$ Published: December 03, 2014
}

This is an open-access article distributed under the terms of the Creative Commons Attribution License, which permits unrestricted use, distribution, and reproduction in any medium, provided the original author and source are credited.

\section{ABSTRACT}

TGF- $\beta 1$, a potent EMT (epithelial-mesenchymal transition) inducer present in the tumor microenvironment, is involved in the metastasis and progression of various carcinomas, including esophageal squamous cell carcinoma (ESCC). TIP30 (30kDa HIV1 Tat interacting protein) is a putative tumor metastasis suppressor. Here, we found TIP30 was decreased in cells undergoing EMT induced by TGF- $\beta 1$, an occurrence that was related to promoter hypermethylation. TGF- $\beta 1$ induced TIP30 hypermethylation via increasing DNMT1 and DNMT3A expression, which could be restored by TGF- $\beta$ antibodies. In our in vitro and in vivo studies, we showed that silence of TIP30 led to EMT, enhanced migrative and invasive abilities of ESCC cells, promoted tumor metastasis in xenografted mice; alternatively, overexpression of TIP30 inhibited TGF$\beta 1$-induced EMT, and metastatic abilities of ESCC cells. Mechanically, TIP30 silencing induced the nuclear translocation and transcriptional activation of $\beta$-catenin in an AKT-dependent manner, which further resulted in the initiation of EMT. Consistently, TIP30 was frequently methylated and downregulated in ESCC patients. Loss of TIP30 correlated with nuclear $\beta$-catenin and aberrant E-cadherin expression. TIP30 was a powerful marker in predicting the prognosis of ESCC. Taken together, our results suggest a novel and critical role of TIP30 involved in TGF- $\beta 1$-induced activation of AKT $/ \beta$-catenin signaling and ESCC metastasis.

\section{INTRODUCTION}

Esophageal cancer, the eighth most common cancer in the world, is composed of two main histologic types: squamous cell carcinoma (ESCC) and adenocarcinoma (EAC) [1]. The main risk factors for ESCC, the predominant type worldwide, include smoking and alcohol abuse, both inflammatory insults to the esophagus [2].
ESCC patients usually have poor prognostic outcomes that are mainly due to metastasis and recurrence after surgery. However, the molecular mechanisms underlying tumor metastasis in ESCC is poorly understood.

Metastasis is a complex process involving acquires of motility and invasiveness properties and disseminates from primary tumors. Evidence suggests that a subset of epithelial tumor cells acquire these properties by 
undergoing EMT, characterized by the loss of cell polarity, and gain of mesenchymal differentiation properties [3, 4]. TGF- $\beta 1$, a potent EMT inducer present in the tumor microenvironment, is involved in the metastasis and progression of various carcinomas, including gastric [5], colorectal [6] and esophageal [7, 8] carcinoma. TGF- $\beta 1$ induces EMT through multiple distinct signaling mechanisms [9]. In addition to its ability to activate receptor-regulated-Smad proteins, TGF- $\beta 1$ can also engage non-Smad-dependent pathways, including the Wnt / $\beta$-catenin, MAPK and Notch pathways, some of which can trigger EMT programs [10-12]. However, the underlying mechanism of how TGF- $\beta 1$ activates those pathways is still unclear.

TIP30, also called CC3 or HTATIP2, is a putative tumor suppressor initially identified by a differential display analysis of mRNA in highly metastatic human variant small cell lung carcinoma (v-SCLC), versus less metastatic classic small cell lung carcinoma (c-SCLC) cell lines [13]. TIP30 is down-regulated in various human tumors due to DNA methylation or posttranscriptional regulation by miR $10 \mathrm{~b}[14,15]$. It's down-regulation associates with metastasis or poor prognosis of human breast cancer [16], lung cancer [17], pancreas cancer [18] and hepatocellular cancer [19]. TIP30 is able to interact with Ets-1 and inhibit Ets-1-mediated transactivation of osteopontin, an important molecule for tumor metastasis in HCC $[20,21]$. Recently, inhibition of the EGFR/AKT signaling pathway by TIP30 was elucidated in breast cancer and hepatocellular carcinoma. We previously reported that TIP30 is downregulated during TGF- $\beta 1$ induced EMT and decreased TIP30 induces properties of EMT and tumor-initiating cells to facilitate tumor metastasis in HCC [19]. However, the precise mechanism of how TGF- $\beta$ regulates TIP30 expression remains unclear. Here, we are able to characterize the methylated regulation of TIP30 by TGF- $\beta 1$, as well as the critical role of TIP30 involved in TGF- $\beta 1$-induced activation of AKT/ $\beta$-catenin signaling and ESCC metastasis.

\section{RESULTS}

\section{TIP30 was negatively correlated with TGF- $\beta 1$ in ESCC cells}

TGF- $\beta 1$ is a classic EMT inducer in many types of epithelial tumors, including ESCC. As shown in Fig. 1A, KYSE30 and KYSE450 cells had an epitheliallike morphology. After treatment with TGF- $\beta 1$, cells underwent a morphologic change from a cobblestone-like cell morphology to a spindle-like, fibroblastic morphology, accompanied with increased cell invasion and migration ability (Fig. 1A and 1B). To better characterize TGF$\beta 1$-induced EMT, we examined the mRNA expressions of EMT-related genes and TIP30 (Fig. 1C). We found that besides typical molecular changes of EMT, TIP30 expression was significantly decreased upon TGF- $\beta 1$ treatment in ESCC cells. To correlate the endogenous expression levels of TIP30 with the levels of TGF- $\beta 1$, we detected the mRNA expressions of TIP30 (Fig. 1D, upper) and the secretion levels of TGF- $\beta 1$ (Fig. 1D, lower) in 6 ESCC cell lines and normal esophageal mucosa cell line Het-1A. These results reveal a strong inverse correlation between TIP30 expression and TGF- $\beta 1$ level (Spearman's $\mathrm{r}=0.93, P=0.03$ ). Further, qRT-PCR and Western blots showed that TGF- $\beta 1$ decreased overall TIP30 expression levels in both dose-dependent (Fig. 1E, left) and timedependent (Fig. 1E, right) manners in KYSE30 cells. In contrast, mRNA expressions of TIP30 were restored in all silenced cell line when treated with anti-TGF- $\beta$ antibody (Fig. 1F). All the above suggested that TIP30 expression was downregulated by TGF- $\beta 1$ in ESCC cells.

\section{TIP30 was frequently methylated and downregulated in ESCC}

There is a typical $\mathrm{CpG}$ island spanning the transcription start site of TIP30 (Fig. 2A), as we described previously [15]. To explore whether hypermethylation of TIP30 is involved in the decreased expression of TIP30, we examined the methylation status of TIP30 in 6 ESCC cell lines and normal esophageal mucosa cell line Het1A (Fig. 2B). Methylation-specific PCR (MSP) results showed that the TIP30 promoter was unmethylated in normal esophageal mucosa cell Het-1A and KYSE30 cells which had abundant TIP30 mRNA expression. In contrast, TIP30 was completely methylated in KYSE150 cells, which had undetectable TIP30 expression. Partial methylation of TIP30 was found in the remaining ESCC cells, which had both methylated and unmethylated alleles. To confirm the MSP results, we further examined TIP30 promoter methylation by conducting bisulfite genomic sequencing (BGS) analysis of 18 individual $\mathrm{CpG}$ sites within its $\mathrm{CpG}$ island (Fig. 2B lower). The result revealed that promoter of TIP30 was frequently methylated in ESCC cells. ESCC cell lines with methylated TIP30 were treated with DNA demethylating agent 5-Aza2'dC, and then MSP and QRT-PCR were performed. The results showed that treatment with 5-Aza-2'dC decreased the methylated MSP products (Fig. 2C) and increased TIP30 mRNA expression (Fig. 2D). Together, these data demonstrate that hypermethylation of $\mathrm{CpG}$ islands results in epigenetic silence of TIP30 in ESCC cell lines.

To investigate the methylation status of TIP30 in human ESCC specimens, MSP was performed in 85 cases of ESCC tissues (T) and 8 cases of normal esophageal mucosa tissues (N, Fig. 2E). The methylation of TIP30 was $62 / 85(72.9 \%)$ in the tumor tissues and only $1 / 8$ $(12.5 \%)$ in the normal esophageal mucosa tissues. The methylation status of TIP30 was further confirmed by BGS 
A

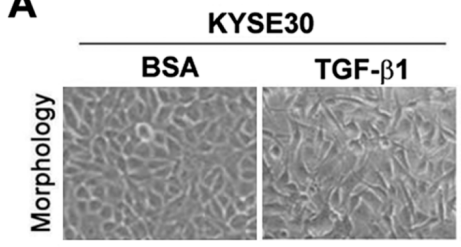

B

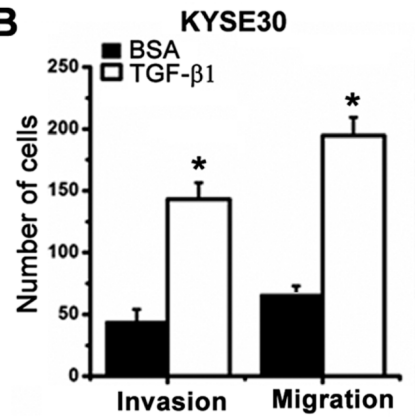

D
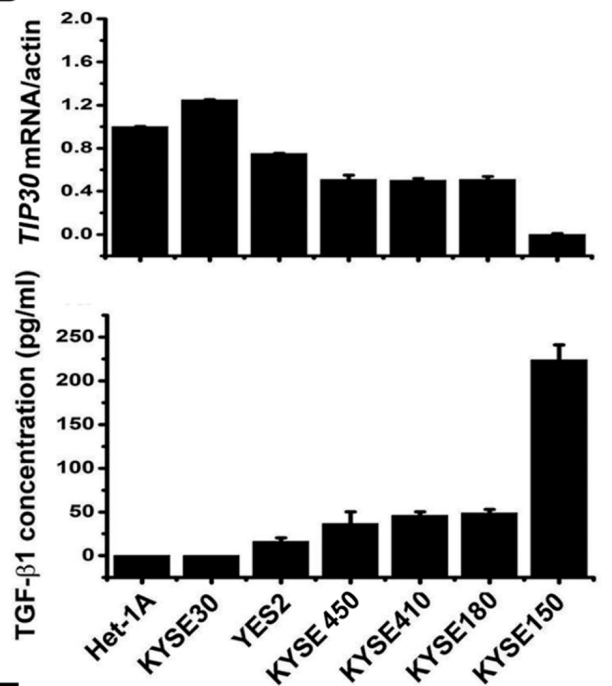

$\mathbf{F}$

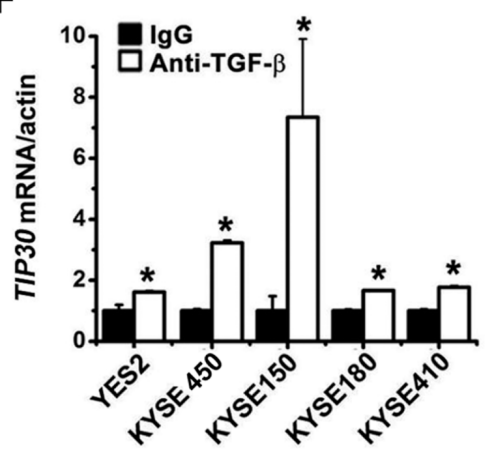

C
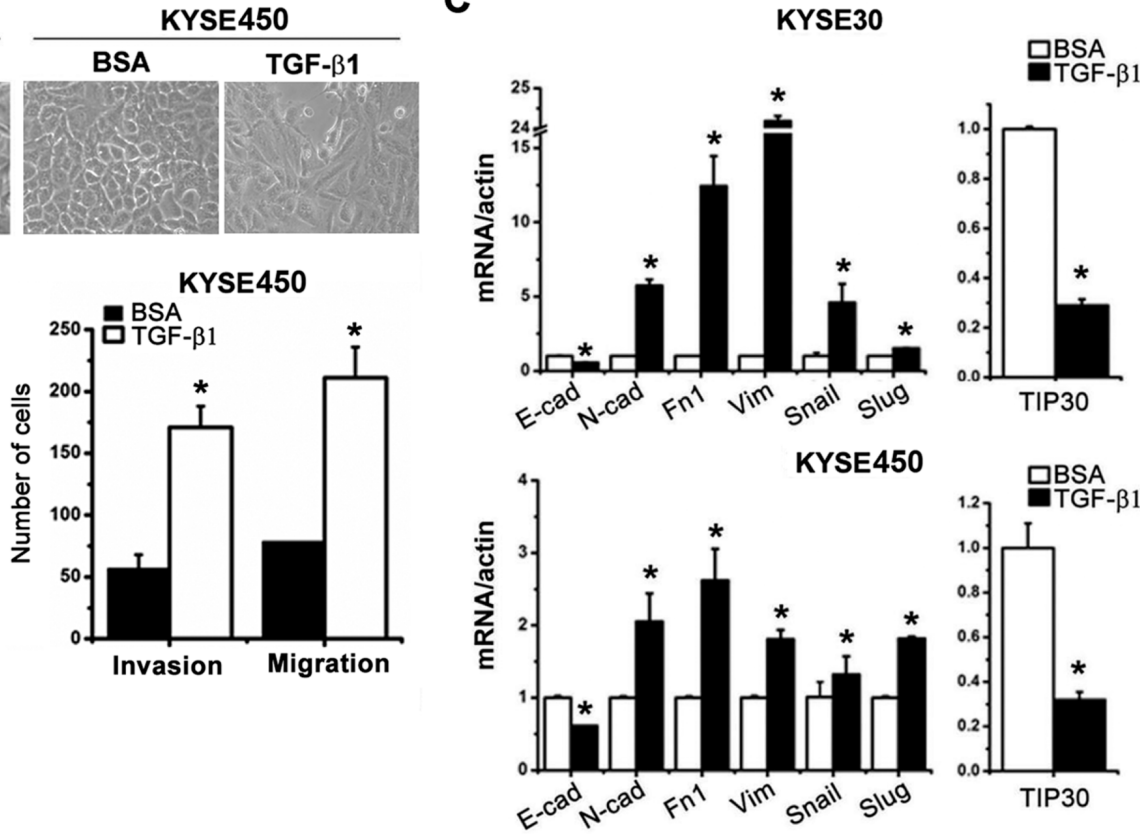

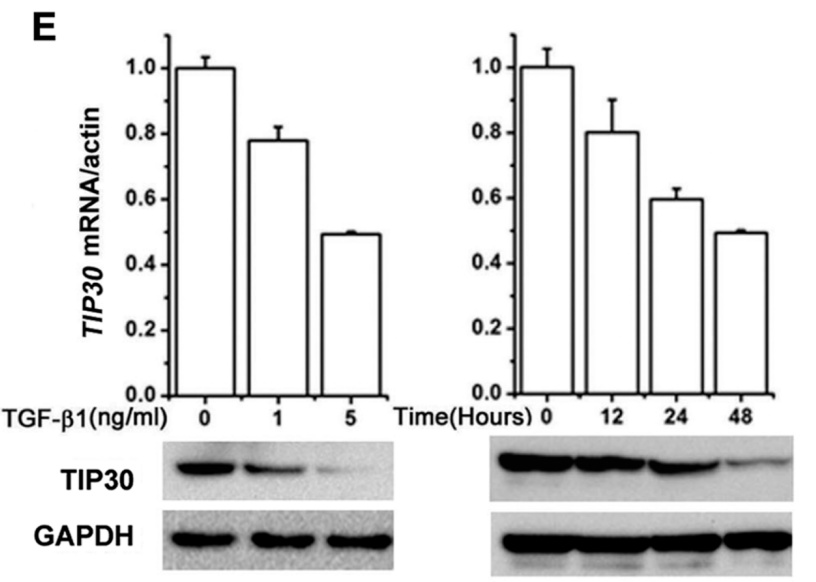

Figure 1: The reverse correlation of TIP30 and TGF- $\beta 1$ levels in ESCC cell lines. KYSE30 and KYSE450 cells were treated with $5 \mathrm{ng} / \mathrm{ml}$ TGF- $\beta 1$ or BSA for 48 hours, (A) morphologies of KYSE30 and KYSE450 were shown by phase-contrast microscopy (magnification, $\times 200$ ); (B) invasion and migration assay were performed, total number of invaded and migrated cells were quantified and compared to the control samples; ${ }^{*} P<0.05$; (C) the mRNA expression levels of EMT-related genes as well as TIP30 were determined by QRT-PCR (E-cad, E-cadherin; N-cad, N-cadherin; Fn1, Fibronectin 1; Vim, Vimentin; ${ }^{*} P<0.05$ ). (D) The expressions of TIP30 mRNA were examined in 6 ESCC cell lines and a normal esophageal mucosa cell line Het-1A by QRT-PCR (upper); TGF- $\beta 1$ concentrations in the cell culture supernatant were measured by specific enzyme-linked immunosorbent assay (ELISA) and normalized to the total number of cells (lower). Data are expressed as pg/ml of TGF- $\beta 1$ per $10^{5}$ cells. (E) KYSE30 cells were stimulated with TGF- $\beta 1$ at indicated concentrations or for defined intervals, and then QRT-PCR and Western blots were performed to determine the expression level of TIP30. (F) ESCC cells were treated with anti-TGF- $\beta$ antibody $(5 \mathrm{ng} / \mathrm{ml})$ for 3 days, and then the expression of TIP30 mRNA was determined by QRT-PCR. Each bar represented the mean \pm sd. of samples measured in triplicate, and each experiment was repeated at least three times. 
(Fig. 2F). The results indicate that TIP30 is frequently hypermethylated in ESCC specimens.

\section{TGF- $\beta 1$ promoted TIP30 methylation through inducing DNMTs expression}

To investigate the effects of TGF- $\beta 1$ on TIP30 methylation, we treated ESCC cells with TGF- $\beta 1$ or antiTGF- $\beta$ antibody before extracting the genomic DNA and subjecting it to MSP analysis. The results showed that TGF- $\beta 1$ induced a decrease in unmethylated promoter alleles and an increase in methylated promoter alleles in KYSE30 cells (Fig. 3A, left). In contrast, anti-TGF- $\beta$ antibody suppressed TIP30 methylation in KYSE450 and KYSE150 cells (Fig. 3A, right). The decreased expression of TIP30 by TGF- $\beta 1$ was independent of canonical TGF- $\beta 1$ signaling, since siRNA-mediated knockdown of Smad3 did not restore TIP30 expression upon TGF- $\beta 1$ treatment (Fig. 3B). The results confirmed that
TGF- $\beta 1$ silences TIP30 expression by inducing promoter methylation.

To further explore the mechanisms by which TGF- $\beta 1$ promotes methylation of TIP30, we analyzed expression of DNMTs. The mRNA expression of DNMT1 and DNMT3A were unchanged after TGF- $\beta 1$ treatment (Fig. 3C). However, the protein expression of DNMT1 and DNMT3A were increased upon TGF- $\beta 1$ treatment in both dose-dependent and time-dependent manners in KYSE30 (Fig. 3D, left and middle). In contrast, the anti-TGF- $\beta$ antibody decreased DNMT1 and DNMT3A expression in KYSE450 and KYSE150 (Fig. 3D, right). To confirm the roles of DNMT1 or DNMT3A on TIP30 expression, specific siRNA against DNMT1 and DNMT3A were used. The results showed that the silencing of DNMT1 or DNMT3A restored TIP30 expression in TGF- $\beta 1$ treated cells (Fig. 3E and F). These data suggest that TGF- $\beta 1$ promotes methylation of TIP30 by increasing expression of DNMT1 and DNMT3A.
A

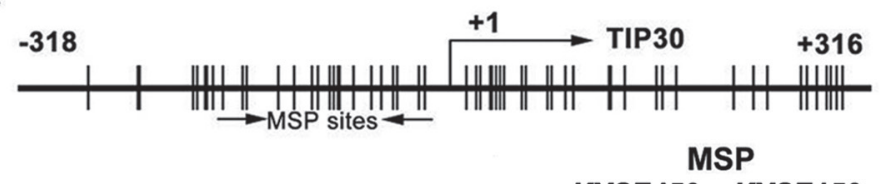

B MSP
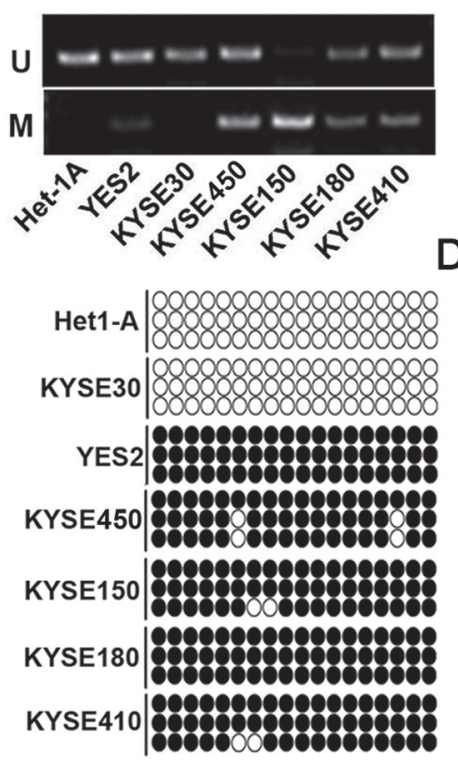

C

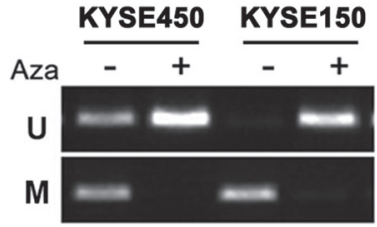

D

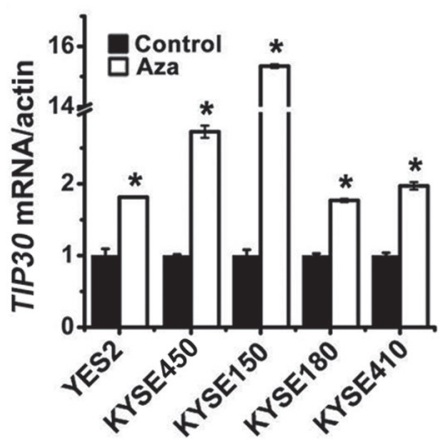

E

MSP

Sam.\# $6 \quad 2122 \quad 40515962 \quad 68$

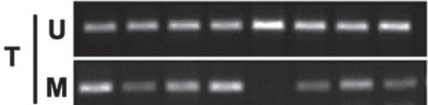

Sam.\#164168169171172173174175

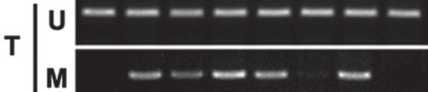

Sam.\# N1 N2 N3 N4 N5 N6 N7 N8

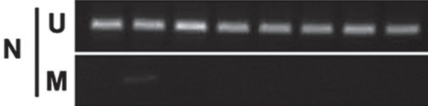

F

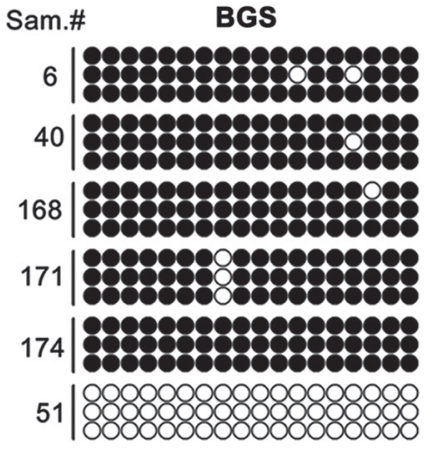

Figure 2: TIP30 was frequently methylated and downregulated in ESCC. (A) The CpG island region of TIP30 is shown. The transcriptional start site is denoted as +1 . The region used in MSP is underlined. (B) Methylation patterns of TIP30 promoter were determined by MSP analysis (upper) and BGS (lower) in 6 ESCC cell lines and a normal esophageal mucosa cell line Het-1A (M, methylated; U, unmethylated; the black circle indicates the methylated cytosine while the white circle indicates the unmethylated cytosine in the dinucleotide CpG). (C) MSP analysis the methylation pattern of TIP30 promoter in KYSE450 and KYSE150 cells after treatment with 5ng/ml of 5-Aza-2_dC for 3 days. (D) ESCC cells were treated with 5ng/ml of 5-Aza-2_dC for 3 days; the expression of TIP30 mRNA was determined by QRT-PCR (error bar indicate SD, standard deviation; ${ }^{*} P<0.05$ ). (E) Representative results of MSP analysis of TIP30 genes in tumor tissues $(\mathrm{T})$ and 8 normal esophageal mucosa tissues $(\mathrm{N})$. (F) Representative results of BGS analysis of TIP30 genes in tumor tissues. Data shown represent three different experiments. 


\section{TIP30 inhibits TGF- $\beta 1$-induced EMT and tumor metastasis}

The effects of TIP30 in TGF- $\beta 1$-regulated EMT and metastatic potential were determined both in vitro and in vivo. KYSE30 cells were transfected with siRNA against TIP30. Silencing TIP30 led to morphologic changes, from square-like epithelial to spindle-like mesenchymal phenotype (Fig. 4A upper). Moreover, E-cadherin expression was decreased, whereas the vimentin expression was increased in the TIP30-depleted cells (Fig. 4B left and Supplemental Fig. 1A). EMT phenotype was also observed in KYSE30 cells stably expressing TIP30 short hairpin RNA (shRNA) (Supplemental Fig. 1B and C). On the other hand, KYSE450 cells were infected with the Lv-TIP30 or Lv-Non control virus and then treated with TGF- $\beta 1$ or BSA for $48 \mathrm{~h}$. Overexpression of TIP30 blocked TGF- $\beta 1$-induced EMT as determined by examination of cell morphology, expression of E-cadherin and Vimentin (Fig. 4A lower and Fig. 4B right). Migration and invasion assay showed that knockdown of TIP30 resulted in a clear and potent migrative and invasive phenotype in KYSE30 cells (Fig. 4C left). In the contrast, overexpression of TIP30 may reduce TGF- $\beta 1$-induced increases in cell invasion and migration (Fig. $4 \mathrm{C}$ middle

A

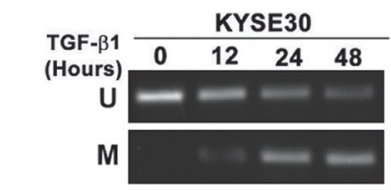

B

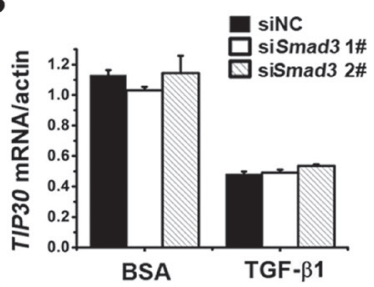

D

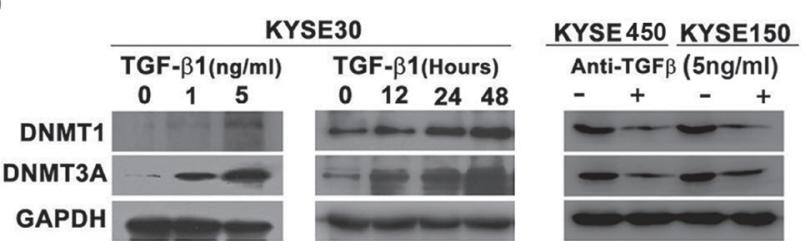

and right). All of these results demonstrate that decrease of TIP30 plays an important role in TGF- $\beta 1$-induce EMT in ESCC cells.

KYSE30 cells were infected with lentivirus expressing shNon or shTIP30 to establish KYSE30-shNon and KYSE30-shTIP30 cells respectively. Cells were then injected into the flanks of nude mice ( $\mathrm{n}=6$ per group). Compared to non-specific RNA interference, knockdown of TIP30 significantly enhanced the growth and invasion of tumor cells (Supplemental Fig. 2) Furthermore, H\&E staining and IHC staining for TIP30, Vimentin and E-cadherin were performed on tumor sections. A clear boundary between the tumor and its adjacent nontumor tissue was often observed in KYSE30-shNon cells generated tumors. However, irregular tumor invasion with a decreased E-cadherin expression and an increased Vimentin expression were observed in tumors induced by KYSE30-shTIP30 cells (Fig. 4D). The in vivo data confirms our in vitro observations that a loss of TIP30 promotes the cell invasion and EMT in ESCC.

To further elucidate the inhibitory effects of TIP30 on tumor metastasis, both experimental and spontaneous metastasis assays were used. KYSE30-shTIP30 and KYSE30-shNon cells were intravenously injected into nude mice. After 8 weeks, the mice were euthanized and the lungs and livers were harvested. The number of
E

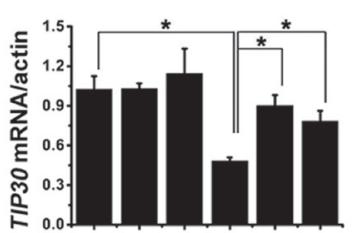

C
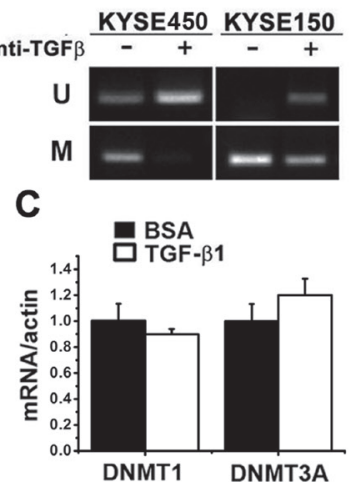

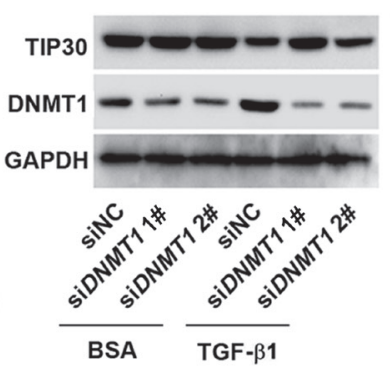

$\mathbf{F}$
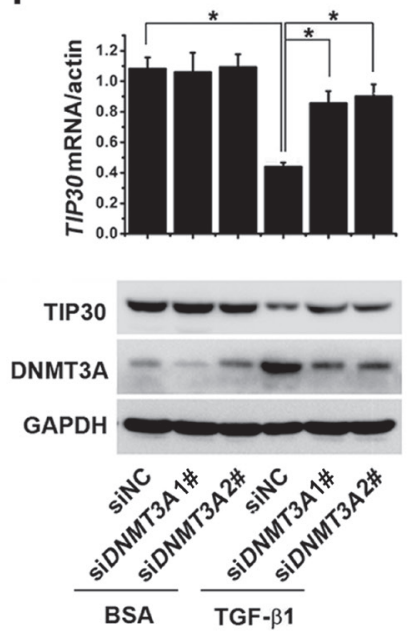

Figure 3: TGF- $\beta 1$ promoted TIP30 methylation through inducing DNMTs expression. (A) KYSE30 cell were treated with TGF- $\beta 1(5 \mathrm{ng} / \mathrm{ml})$ for defined intervals, and KYSE450/KYSE150 cells were treated with anti-TGF- $\beta$ antibody $(5 \mathrm{ng} / \mathrm{ml})$ for three days, then the methylation pattern of TIP30 promoter is determined by MSP analysis. (B) KYSE30 cells transfected with siRNA against Smad3, and then treated with or without TGF- $\beta 1,48$ hours later QRT-PCR were performed to determine the expression of TIP30. (C) KYSE30 cells were treated with or without TGF- $\beta 1,48$ hours later QRT-PCR were performed to determine the mRNA expression of DNMT1 and DNMT3A. (D) KYSE30 cell were treated with TGF- $\beta 1$ at indicated concentrations or for defined intervals, and KYSE450/KYSE150 cells were treated with anti-TGF- $\beta$ antibody $(5 \mathrm{ng} / \mathrm{ml})$ for three days, then expressions of DNMT1 and DNMT3A were determined by Western blots. KYSE30 cells transfected with siRNA against DNMT1 (E) or DNMT3A (F), and then treated with or without TGF- $\beta 1,48$ hours later QRT-PCR and Western Blots were performed to determine the expression of TIP30; $* P<0.05$. Each bar represented the mean \pm sd. of samples measured in triplicate, and each experiment was repeated at least three times. 
A

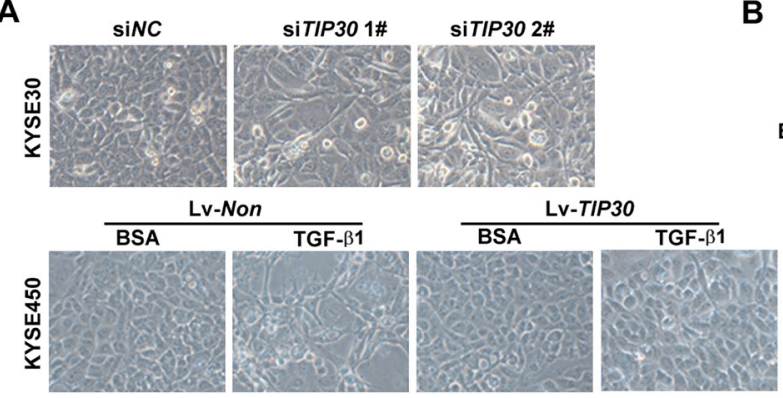

B

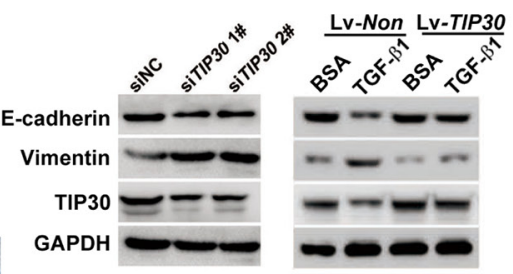

C

KYSE30

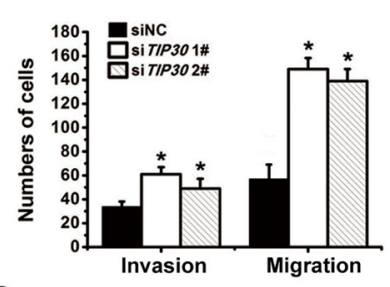

D
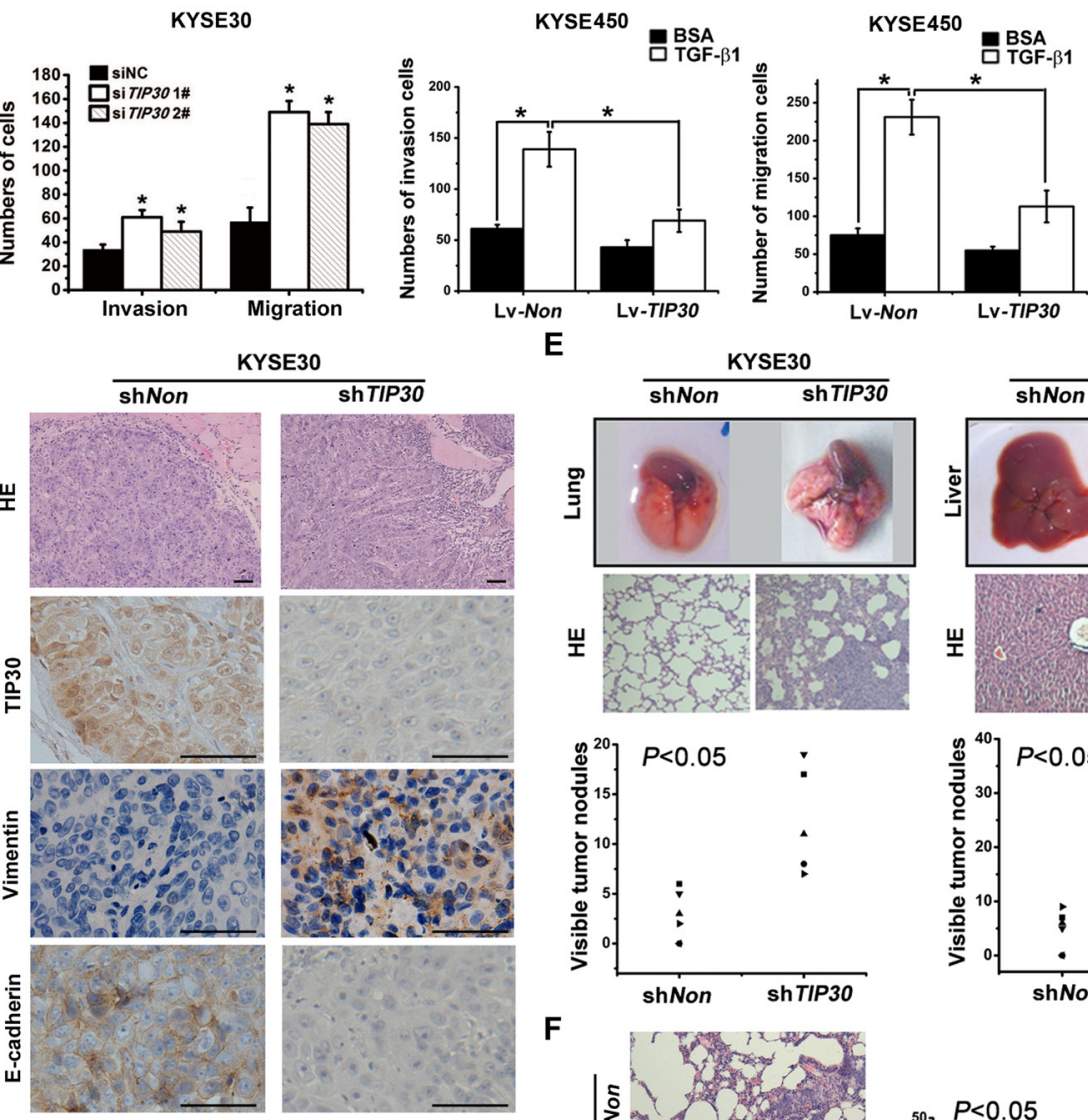

E

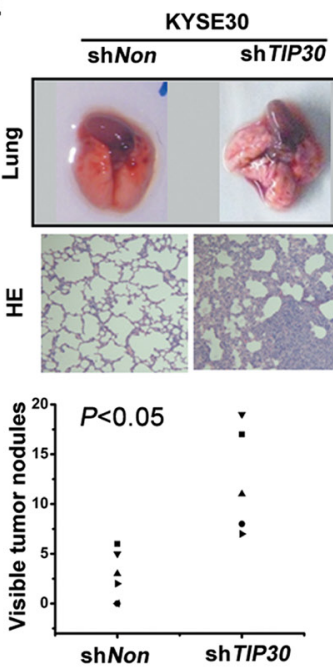

$\frac{\text { KYSE30 }}{\text { shNon } \quad \text { ShTIP3O }}$

$\mathbf{F}$
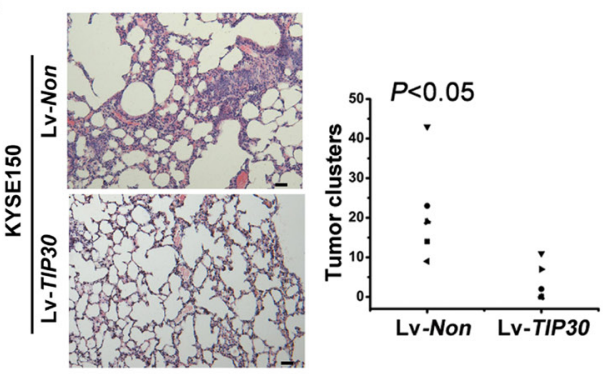

Figure 4: TIP30 inhibited TGF- $\beta 1$-induced EMT and tumor metastasis. KYSE30 cells transfected with siRNA against TIP30 for 48 hours; KYSE450-TIP30 cells and KYSE450-Non cells were treated with or without TGF- $\beta 1$ for 48 hours; (A) morphologies were shown by phase-contrast microscopy (magnification, $\times 200$ ); (B) the expressions of E-cadherin, Vimentin and TIP30 were determined by Western Blots; $(C)$ invasion and migration assay were performed, total number of invaded and migrated cells were quantified and compared to the control samples; error bar indicate SD, ${ }^{*} P<0.05$. (D) Male Balb/c nude mice were injected subcutaneously with KYSE30-shTIP30 cells or KYSE30-shNon cells into the right flank of each animal. HE-staining and IHC staining for TIP30, Vimentin and E-cadherin on

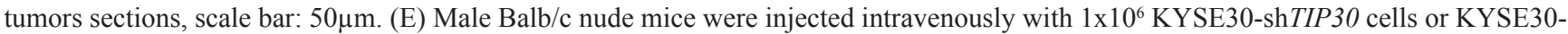
shNon cells through the tail vein, and then lung metastasis (left) and liver metastasis (right) were evaluated. The upper, metastatic nodules on the surface of the lung and liver are shown; the middle, representative H\&E staining of lung and liver are shown; the lower, the numbers of nodules were quantified and values for each group are denoted $\left({ }^{*} P<0.05\right.$, Student's $t$ test). (F) Male Balb/c nude mice were injected subcutaneously with KYSE150-TIP30 cells or KYSE150-Non cells into the right flank of each animal. Representative lung tissue sections by HE-staining from each group were shown in the left. Scale bar: $50 \mu \mathrm{m}$. The number of lung metastatic foci in each group was calculated under microscope in the right $\left({ }^{*} P<0.05\right.$, Student's $t$ test). 
metastatic nodules on the surface of the lungs and livers was significantly higher in mice injected with KYSE30shTIP30 cells than in mice injected with KYSE30-shNon cells (Fig. 4E, lower). Histological studies confirmed that the lesions were caused by extravasation and subsequent tumor growth of KYSE30 cells into the lungs and livers (Fig. 4E, middle). Meanwhile, KYSE150 cells infected with Lv-TIP30 or Lv-Non control virus were injected subcutaneously into each mouse. Spontaneous metastasis assays showed that overexpression of TIP30 significantly reduced the incidence of lung metastases in nude mice
(Fig. 4F). Since the tumors displayed severe liquefactive necrosis, the volume was not detected. All the above revealed that TIP30 negatively regulates tumor metastasis in ESCC in vivo.

\section{TIP30 blocked $\beta$-catenin signaling activated by TGF- $\beta 1$}

$\beta$-catenin has long been used as a marker for EMT. It not only functions as a major component of cell-cell
A

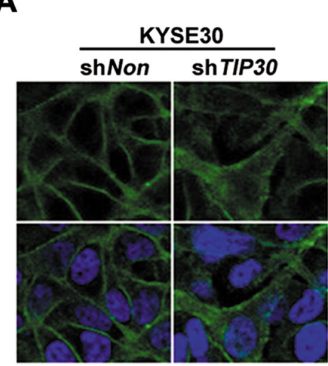

C

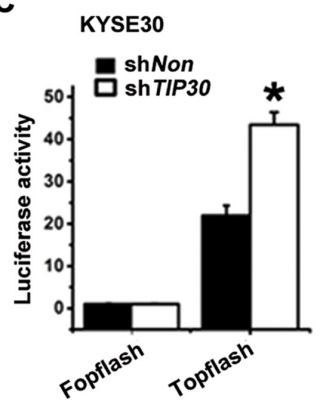

E

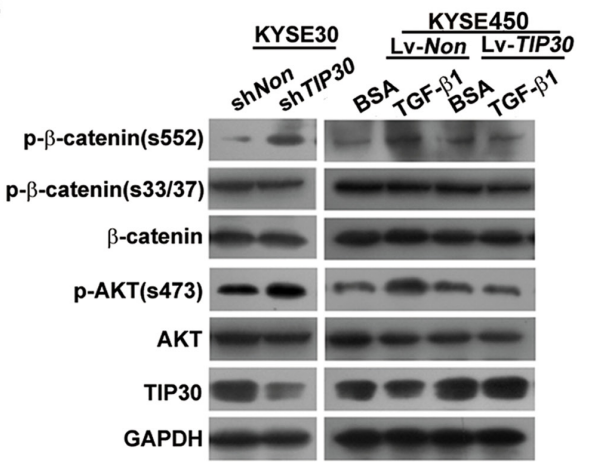

KYSE450

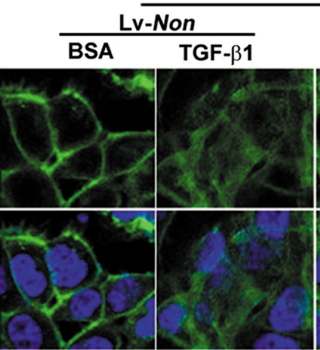

KYSE450

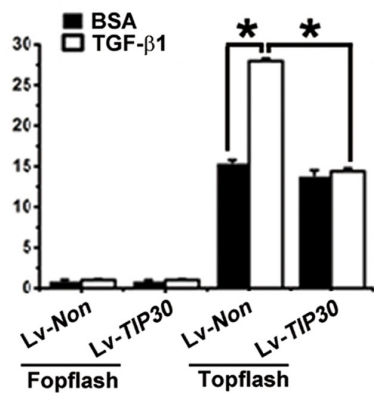

D

B
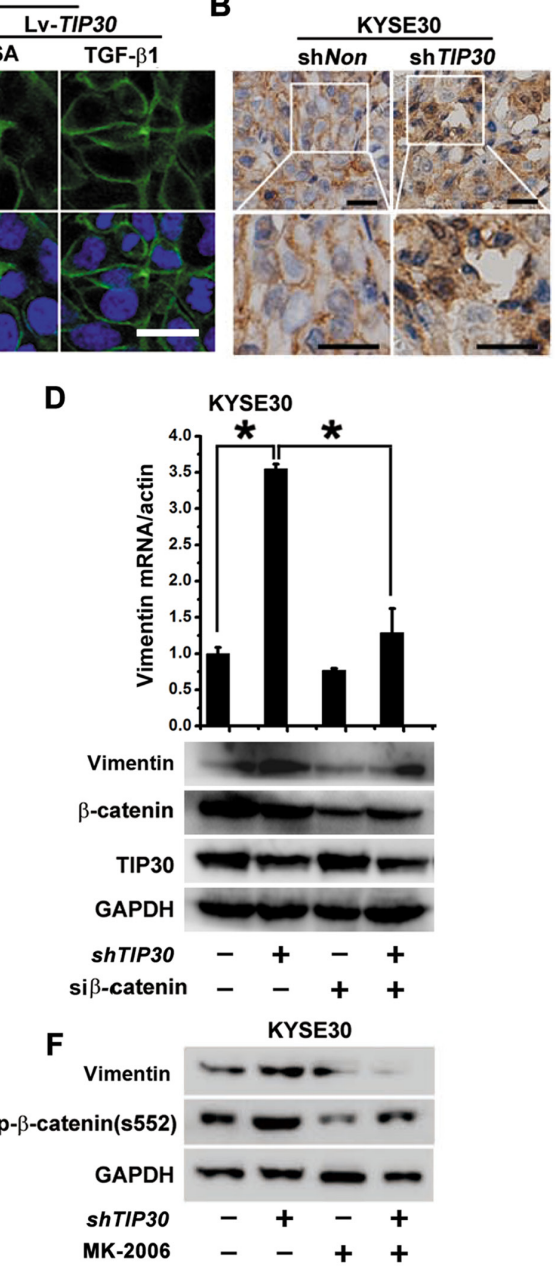

Figure 5: TIP30 blocked $\boldsymbol{\beta}$-catenin signaling activated by TGF- $\beta 1$. (A, C and E) KYSE30 cells were infected with Lv-shTIP30 to downregulated TIP30 expression; KYSE450 cells were infected with LV-TIP30 to overexpression TIP30, three days later cells were treated with or without TGF- $\beta 1$ for 48 hours. (A) IF analysis of $\beta$-catenin were performed. The green signals represent the staining of $\beta$-catenin and the blue signal represents the DAPI-stained nuclei; scale bar: $20 \mu \mathrm{m}$. (B) After 4 weeks' orthotopic xenograft transplantation of KYSE30-shTIP30 cells or KYSE30-shNon cells in nude mice, tumors derived from each group were immunostained for $\beta$-catenin, scale bar: $50 \mu \mathrm{m}$. (C) TOP-Flash reporter gene assays were used to determine the transcriptional activity of $\beta$-catenin (error bar indicate SD, * $P<0.05$ ). (D) KYSE30-shTIP30 cells or KYSE30-shNon cells were transfected with siRNA against $\beta$-catenin, 72 hours later expression of Vimentin were detected by QRT-PCR and Western Blots (error bar indicate SD, $* P<0.05$ ). (E) Phosphorylation levels and total expression levels of $\beta$-catenin and AKT were determined by Western Blots using specific antibodies. (F) KYSE30-shTIP30 cells or KYSE30-shNon cells were treated with MK-2206, 48 hours later expression of Vimentin and p- $\beta$-catenin (s552) were detected by Western Blots $(* P<0.05$ ). Data shown represent three different experiments. 
adhesion, both also mediates transcriptional activation. A high-magnification picture of $\beta$-catenin staining showed downregulation of TIP30 promoted $\beta$-catenin to become disassociated from cell contacts and become translocated into the cytosol. Overexpression of TIP30 inhibits TGF- $\beta 1$-induced redistribution of $\beta$-catenin (Fig. 5A). Consistent with the in vitro experimental results, cytosol and nucleus staining of $\beta$-catenin were found in KYSE30shTIP30 cells generated tumors, while the control tumors showed a membranous staining of $\beta$-catenin (Fig. 5B). Because the cytoplasmic relocalization of $\beta$-catenin results in an increased pool of the protein that is able to move to the nucleus and stimulate transcription [22], we examined the transcriptional activation of the $\beta$-catenin reporter, TOP-flash. As expected, TIP30 silence sharply increased $\beta$-catenin-dependent transcriptional activity. Conversely, overexpression of TIP30 suppressed TGF- $\beta 1$-induced activation of $\beta$-catenin (Fig. 5C). Previous study shows that $\beta$-catenin targets the Vimentin and ZEB1 genes for their transcription during EMT [23, 24]. In our study, TIP30 regulates Vimentin expression but not ZEB1 in ESCC (Supplemental Fig. 1A). To confirm the importance of $\beta$-catenin in increased expression of Vimentin induced by TIP30 silence, siRNA against $\beta$-catenin was used. The results showed TIP30 silence-induced Vimentin expression was significantly blocked in $\beta$-catenin-depleted cells (Fig. 5D). To underlie the regulatory mechanism of $\beta$-catenin activity by TIP30, the phosphorylation status of $\beta$-catenin was examined via western blots with indicated antibodies (Fig. 5E). GSK-3 $\beta$ mediated phosphorylation of S33/37 did not change upon TIP30 depletion or TGF- $\beta 1$ treatment. However, AKT mediated phosphorylation of

A
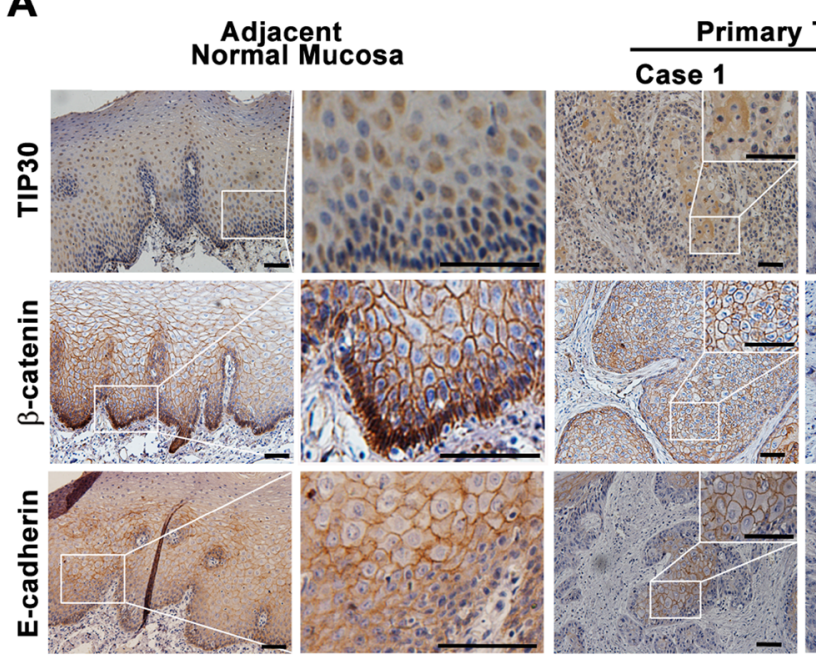

y Tumor

Case 2
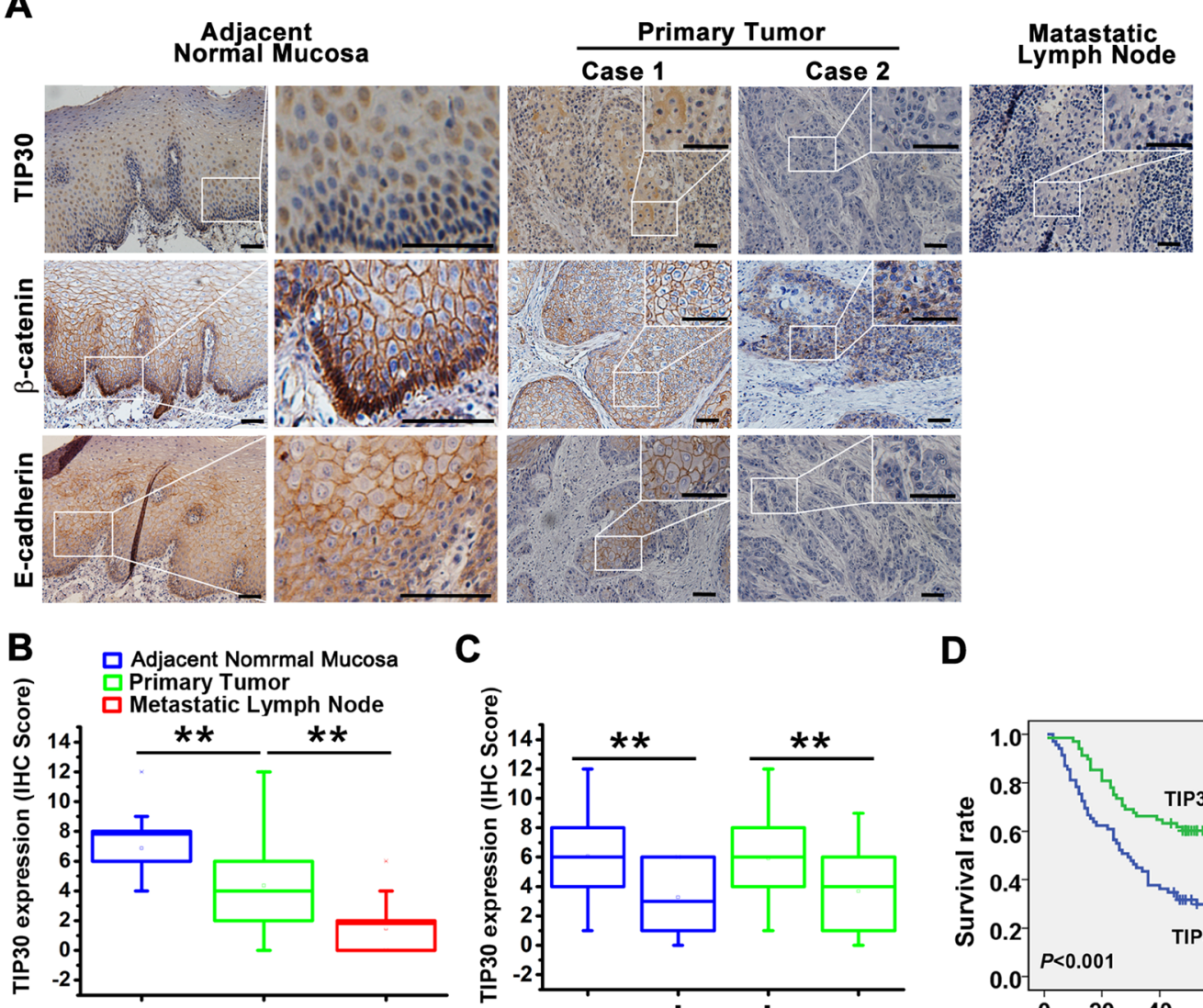

C

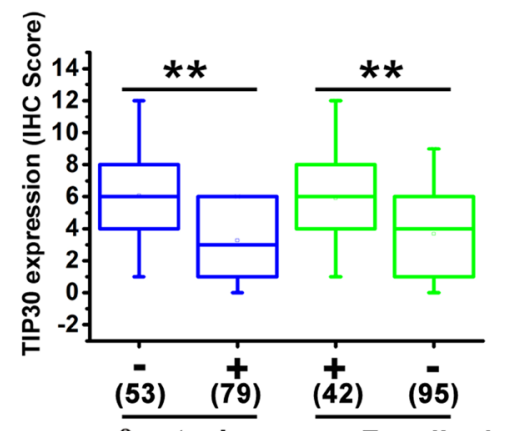

D
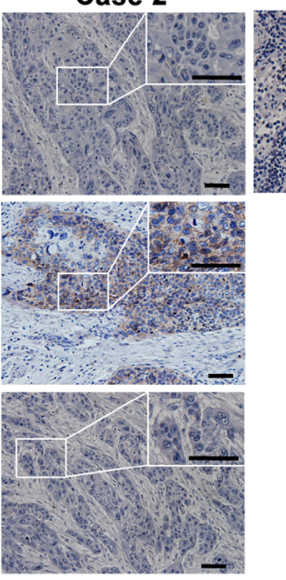

D

\section{$\beta$-catenin E-cadherin \\ nucleus staining junctional staining}

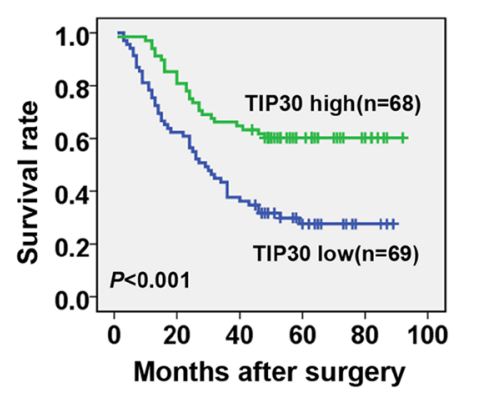

Figure 6: TIP30 expression correlated with EMT status in human ESCC, and is indicative of patient survival. (A) Representative images of TIP30, $\beta$-catenin and E-cadherin in primary tumor tissue, the adjacent normal mucosa and metastatic lymph node examined by IHC. Scale bar: $50 \mu \mathrm{m}$. (B) Comparisons of TIP30 expression level among different groups, including the adjacent normal mucosa, primary tumor tissue and metastatic lymph node (Mann-Whitney U test: $* * P<0.01$ ). (C) The relationships between TIP30 expression and protein expression of $\beta$-catenin and E-cadherin were analysed (Mann-Whitney U-test: **P<0.01). Nuclear $\beta$-catenin negative $n=53$ and nuclear $\beta$-catenin positive $n=79$; junctional E-cadherin positive $n=42$ and junctional E-cadherin negative $n=95$. Spread of data denoted by box-and-whisker plot, the central box represents the value from the lower to upper quartile (25th-75th percentile). The middle line represents the median. The whisker ends 1 and 99 percentiles. (D) Kaplan-Meier survival analysis of OS in ESCC patients based on TIP30 expression. Differences in survival between TIP30 low expression group and TIP30 high expression group were evaluated by the log-rank test. 
Table 1: The associations of TIP30 expression with clinicopathological characteristics in ESCC patients

\begin{tabular}{|c|c|c|c|c|}
\hline & Total & Low expression & High expression & $P$ value \\
\hline Age (means. \pm d. years) & $59.48 \pm 8.68$ & $59.65 \pm 8.74$ & $59.33 \pm 8.75$ & NS. \\
\hline Gender & & & & NS. \\
\hline Male & 83 & 44 & 39 & \\
\hline Female & 54 & 25 & 29 & \\
\hline Tumor location & & & & NS. \\
\hline Upper & 2 & 2 & 0 & \\
\hline Mid-thoracic & 86 & 41 & 45 & \\
\hline Lower & 49 & 26 & 23 & \\
\hline Histlogy & & & & NS. \\
\hline Well- Moderate & 108 & 50 & 58 & \\
\hline Poor & 29 & 19 & 10 & \\
\hline pT & & & & 0.002 \\
\hline $\mathrm{pT}_{1-2}$ & 81 & 32 & 49 & \\
\hline $\mathrm{pT}_{3-4}$ & 56 & 37 & 19 & \\
\hline $\mathrm{pN}$ & & & & 0.042 \\
\hline $\mathrm{pN}_{0}$ & 25 & 8 & 17 & \\
\hline $\mathrm{pN}_{1}$ & 112 & 61 & 51 & \\
\hline $\mathrm{pM}$ & & & & NS. \\
\hline $\mathrm{pM}_{0}$ & 113 & 56 & 57 & \\
\hline $\mathrm{pM}_{1}$ & 24 & 13 & 11 & \\
\hline TNM Stage & & & & 0.002 . \\
\hline I-II & 81 & 32 & 49 & \\
\hline III-IV & 56 & 37 & 19 & \\
\hline
\end{tabular}

S552 was significantly increased after TIP30 depletion and TGF- $\beta 1$ treatment. Furthermore, TGF- $\beta 1$ mediated $\beta$-catenin phosphorylated at S552 was blocked by TIP30 overexpression. The results indicate that TIP30 inhibits phosphorylate of $\beta$-catenin at S552 and suppresses activation of $\beta$-catenin. Recent reports suggest that a TIP30 protein complex regulates EGFR endocytosis, resulting in the inhibition of AKT activation $[25,26]$. Phosphorylation and activity of AKT were also detected, as shown in Fig. 5E. TIP30 silence significantly increased AKT activation, and overexpression of TIP30 inhibits TGF- $\beta 1$ mediated AKT activation. Furthermore, blockage of AKT by MK-2206 attenuated TIP30 decrease-induced activation of $\beta$-catenin and upregulation of Vimentin (Fig. $5 \mathrm{~F})$. Together, we conclude that decreased expression of TIP30 facilitates TGF- $\beta 1$-mediated AKT/ $\beta$-catenin activation.

\section{Reduced TIP30 expression predicted a poor prognosis in ESCC patients}

The expression of TIP30 was examined by IHC in 137 primary tumors and paired adjacent normal mucosa, as well as 62 metastatic lymph nodes (Fig. 6A). In the normal epithelial cells, TIP30 showed intense staining mainly in the nucleus just above basal cell layer. In the tumor cells, TIP30 staining was mainly detected in the cytoplasm and significant weaker than that in the normal epithelial cells. Mann-Whitney U test revealed that the immunostaining score of TIP30 was highest in the adjacent normal mucosa and lowest in the metastatic lymph nodes (Fig. 6B).

On the basis of the TIP30 expression in tumor cells, 137 patients with ESCC were divided into two groups: the high-expression $(\mathrm{n}=68)$ and low-expression group $(n=69)$. The correlations of TIP30 expression and clinicopathologic features were further analyzed. TIP30 expression was inversely associated with the depth of tumor invasion $(P=0.002)$, lymph node metastasis $(P=0.042)$ and advance stage $(P=0.002)$. However, there was no significant correlation between TIP30 expression with age, gender, tumor location, tumor differentiation or distant metastasis (Table 1).

Moreover, we also detected $\beta$-catenin and E-cadherin expression levels in the ESCC tissues and paired adjacent normal mucosa (Fig. 6A), in the normal epithelial cells, $\beta$-catenin and E-cadherin showed unequivocal and strong membranous staining just above basal cell layer, whereas, in the basal cell layer, $\beta$-catenin located mainly 
in the nucleus. In the tumor tissues, 59.8\% (79/132) had nucleus positive staining of $\beta$-catenin and $69.3 \%(95 / 137)$ had aberrant E-cadherin protein expression with negative staining or less than $70 \%$ membranous staining. We found loss of TIP30 correlated with nuclear $\beta$-catenin, and aberrant E-cadherin expression $(P<0.001$, Mann-Whitney U test, Fig. 6C).

The potential associations between TIP30 expression and overall survival (OS) evaluated in the 137 patients included in the present study. Log-rank test showed that ESCC patients with low TIP30 expression experienced poor overall survival (OS) than patients with high TIP30 expression (median survival time, 29 months vs. 49 months; $P<0.001$; Fig. 6E). By univariate analysis, tumor differentiation, TNM stage and TIP30 low expression were prognostic factors for OS. Nevertheless, multivariate analysis showed that downregulation of TIP30 and tumor differentiation were 2 independent prognostic predictors for ESCC patients enrolled in this study (Supplemental Table 1). Thus, decreased expression of TIP30 may serve as a prognostic indicator for patients with ESCC.

\section{DISCUSSION}

TGF- $\beta 1$, a potent EMT inducer present in the tumor microenvironment, is involved in the metastasis and progression of many types of carcinomas including esophageal carcinoma. TIP30 is a putative tumor metastasis suppressor and its expression and function in ESCC remains unknown. This study reveals a novel unique modulatory role of TIP30 in TGF- $\beta$-mediated EMT and tumor metastasis in human esophageal cancer.

Here we found that TIP30 expression was negatively correlated with TGF- $\beta 1$ in ESCC cells. TGF- $\beta 1$ decrease TIP30 expression levels in both dose-dependent and time-dependent manners. So far, we know less about the regulation mechanism of TIP30. Previous studies have suggested that the expression of TIP30 could be activated by JAK/STAT3 pathway or suppressed by DNA methylation and mir-10b. It was reported that Sorafenib, a tyrosine kinase inhibitor (TKI), decreased expression of TIP30 via JAK/STAT3 signaling in HCC [27]. In PDAC, TIP30 is a direct target of mir-10b. A typical $\mathrm{CpG}$ island is found in the promoter of TIP30 and TIP30 is frequently metylated in hepatocarcinoma and breast cancer $[15,16]$. We examined methylation status of TIP30 in ESCC cell lines and ESCC patients to find that TIP30 is also frequently hypermethylated in both ESCC cell lines and ESCC patients. Furthermore, the methylation statutes of TIP30 are positively correlated with the levels of TGF- $\beta 1$ in ESCC cell lines. A recent study suggested that TGF- $\beta 1$ also plays an important and controversial role in the regulation of DNA methylation. TGF- $\beta 1$ may increase DNMT1/3A expression and cause nuclear translocation of DNMT1/3A in prostate cancer and kidney fibrogenesis $[28,29]$. TGF- $\beta 1$ may also decrease expression of DNMT1/3B in HCC cells [30]. DNMT1 has been implicated primarily in the maintenance of methylation patterns that occurs during cellular replication and preferentially methylates hemimethylated DNA[31]. We demonstrate that TIP30 can be methylated by TGF- $\beta 1$ via up-regulation of DNMT1 and DNMT3A. TGF- $\beta 1$ did not change the mRNA expression of DNMT1 and DNMT3A, but increased their protein level directly, this may be the reason that methylation and downregulation of TIP30 occurred at early time phases. However, it remains unclear how TGF- $\beta 1$ regulates DNMTs protein levels. It has reported posttranslational modifications of acetylation and ubiquitination, as well as regulation of micoRNA were involved in expression regulation of DNMTs. The regulation of TIP30 expression by TGF- $\beta 1$ implies a potential role of TIP30 in TGF- $\beta 1$-mediated biological functions.

During cancer progression, TGF- $\beta 1$ frequently switches from tumor suppressor to tumor promoter [32, 33]. Oncogenic signals may blunt TGF- $\beta$-induced growth arrest and apoptosis, while enhancing TGF- $\beta$-induced proinvasive and pro-metastatic responses [11, 34, 35]. This may involve a change in the balance between canonical SMAD signaling and non-SMAD signaling [12]. Our results shows that in ESCC cells, TGF- $\beta 1$ induces a typical EMT phenotype accompany with increased cell invasion and migration. Further, we found downregulation of TIP30 may also initiate EMT and increase properties of metastasis, but over-expression of TIP30 may partially inhibit TGF- $\beta 1$-induced EMT and pro-metastatic responses. The results indicate that TGF- $\beta 1$-induced EMT and pro-metastatic responses were mediated partially by silence of TIP30. We also demonstrate that TIP30 may inhibit phosphorylation and activation of $\beta$-catenin. Our data shows that silence of TIP30 facilitates TGF- $\beta 1$ mediated activation of AKT/ $\beta$-catenin signaling, which subsequently induces EMT and pro-metastatic responses.

Our findings present the inhibition effects and the underlying mechanism of TIP30 in tumor metastasis and EMT, and also provide new insights into the molecular mechanisms of TGF- $\beta 1$-mediated tumor progression.

\section{MATERIALS AND METHODS}

\section{Cell culture and lentiviral infection}

ESCC cell lines (YES2, KYSE30, KYSE450, KYSE150, KYSE180 and KYSE410) were cultured at $37^{\circ} \mathrm{C}$ in an atmosphere containing 5\% CO2 in RPMI 1640 medium supplemented with $10 \%$ fetal bovine serum. A normal esophageal cell line Het-1A was cultured in LHC-9 medium supplemented with $2 \%$ fetal bovine serum. Beijing Microread Gene Technology Co, Ltd. used short tandem repeat profiling to authenticate KYSE30, 
KYSE150 and KYSE450 cell lines on Nov. 2013. All the cells were also periodically authenticated by morphologic inspection and tested for Mycoplasma contamination. TGF- $\beta 1$ and TGF- $\beta$ antibody treatment were performed at the indicated concentration (TGF- $\beta$, Peprotech; TGF- $\beta$ antibody, clone 1D11, R\&D Systems). 5-Aza-2 Deoxycytidine (5-Aza-2_dC) (Sigma-Aldrich) treatment was performed using 10uM of 5-Aza-2_dC for 3 days. TIP30 depletion and overexpression experiments were performed by infection of cells with shRNA-expression or TIP30-expression lentivirus using 293T cells as packaging cell lines, as described previously [17]. Sequence of siRNA designed against TIP30, DNMT1, DNMT3A, Smad 3 and $\beta$-catenin can be obtained from Supplemental Table 2 .

\section{RNA extraction and reverse transcription PCR}

Total RNA was isolated using Trizol reagent (Invitrogen). First-strand cDNA was generated using the PrimeScript RT reagent Kit (TAKARA). Analysis of mRNA levels was performed on a 7500 Fast Real-Time PCR System (Applied Biosystems) with SYBR Greenbased real-time PCR. Actin was used as an endogenous control to normalize the amount of total RNA in each sample. The primer sequences can be obtained from Supplemental Table 3.

\section{Western Blots}

Total cell lysate was prepared in $1 \times$ SDS buffer. Proteins at the same amount were separated by SDSPAGE and transferred onto PDVF membranes. After probing with individual antibodies, antigen-antibody complex was visualized by enhanced chemiluminescence's reagents Supersignal (Pierce Biotechnology). The primary antibodies specific against E-cadherin, Vimentin, DNMT1, DNMT3A, p-S552- $\beta$-catenin and p-S33/37- $\beta$ catenin were from Cell Signaling Technology (Beverly, $\mathrm{MA})$; the $\beta$-catenin antibody was from BD Biosciences (SanJose, CA), the GAPDH antibody was from Kangchen Biothechnology Company (Guangzhou, P.R. China); the TIP30 antibody was described previously [17].

\section{Immunofluorescence staining}

Cells were grown on glass chamber slides fixed with $4 \%$ paraformaldehyde/PBS. permeabilized with $0.2 \%$ Triton X-100/PBS, and blocked with $10 \%$ goat serum in PBS. Cells were incubated with primary antibodies against $\beta$-catenin (1:500) (BD Biosciences) at $4^{\circ} \mathrm{C}$ overnight, then incubated with a goat anti-mouse Alex Flour 488 antibody(Invitrogen) and stained with DAPI(Invitrogen). All matched samples were photographed (control and test) a confocal laser-scanning microscope (FLUOVIEW FV1000).

\section{DNA Extraction and Methylation-Specific PCR (MSP) Analysis}

Genomic DNA was extracted from $5 \times 10^{6}$ cells or $10 \mathrm{mg}$ tissue using QIAamp DNA Mini Kit (Qiagen). Genomic DNA was treated with sodium bisulfite has been described [36]. DNA $(5 \mu \mathrm{g})$ was denatured in $33 \mu \mathrm{l}$ of $0.3 \mathrm{~mol} / \mathrm{L} \mathrm{NaOH}$ at $37^{\circ} \mathrm{C}$ for 15 minutes, without using restriction endonuclease. Denatured DNA was mixed directly with $333 \mu$ of bisulfite solution and treated in darkness. The bisulfite solution was prepared as either $2.4 \mathrm{~mol} / \mathrm{L}$ sodium metabisulfite $(\mathrm{pH}$ 5.0-5.2) (SigmaAldrich) $/ 0.5 \mathrm{mmol} / \mathrm{L}$ hydroquinone (Sigma-Aldrich) for a 4-hour treatment 31 or $3.1 \mathrm{~mol} / \mathrm{L}$ sodium bisulfite ( $\mathrm{pH}$ 5.0-5.2) (Sigma-Aldrich) $/ 0.5 \mathrm{mmol} / \mathrm{L}$ hydroquinone for a 16-hour treatment. DNA was desalted and purified using the QIAEX II Gel Extraction Kit (Qiagen). DNA was then treated with $0.3 \mathrm{~mol} / \mathrm{L} \mathrm{NaOH}$ at $37^{\circ} \mathrm{C}$ for 15 minutes and precipitated with $3 \mathrm{~mol} / \mathrm{L}$ ammonium acetate and 3 volumes of ethanol. Recovered DNA was purified again then dissolved in 20-50 $\mu$ l of TE buffer ( $\mathrm{pH} 8.0$ ) and stored at $-20^{\circ} \mathrm{C}$. MSP was performed using Taq Gold polymerase (Applied Biosystems) as described previously. MSP products were subcloned into pGEM-T Vector (Promega) and transformed into Escherichia coli. Candidate plasmid clones were sequenced by Huada Scientific (Beijing, P.R. China).

\section{Quantification of TGF- $\beta 1$}

ESCC cells were cultured in fresh serum-free media for 24 hours, and then total TGF- $\beta 1$ in the cell culture supernatant was measured by specific enzymelinked immunosorbent assay (ELISA) (Peprotech). TGF- $\beta 1$ concentration was normalized to number of cells, determined by cell counting with a hemocytometer. Data are expressed as $\mathrm{pg} / \mathrm{ml}$ of TGF- $\beta 1$ per $10^{5}$ cells.

\section{Transwell Migration and Invasion Assay}

Transwell migration assays were quantified in vitro using Transwell chambers with polycarbonate membrane filters ( $8 \mu \mathrm{m}$ pore size; Corning) according to the manufacturer's instructions. In brief, the lower chamber was filled with $0.6 \mathrm{ml}$ medium containing $20 \%$ fetal bovine serum and $0.2 \mathrm{ml}$ of medium that contained $3 \times 105$ cells under serum-starving conditions was plated in the upper chamber and incubated at $37^{\circ} \mathrm{C}$ for 48 hours. Then cells that had not migrated were removed from the upper face of filters using cotton swabs. The cells that migrated through the membrane and attached to the bottom of the 
membrane were fixed and stained with crystal violet. Images of five random fields were captured from each membrane and the number of migratory cells was counted, and the extent of migration was expressed as the average number of cells per microscopic field at a magnification of 100. The mean of triplicate assays for each experimental condition was used. Similar inserts coated with Matrigel (Chemicon) were used to determine invasive potential in invasion assay. Two independent investigators were blinded when reading the migration and invasion assays.

\section{TOP-flash luciferase assays}

ESCC cells were cotransfected with pTOP-flash or pFOP-flash and Renilla vector (pRL-TK) using Lipofectamine 2000 (Invitrogen) in triplicate. After 24 hours cells were treated with or without $5 \mu \mathrm{M}$ of TGF- $\beta 1$ for 48 hours. The cells were then lysated and analyzed with the Dual Luciferase Kit (Promega) on a Centro XS 3 LB 960 (Berthold Technology GmbH \& Co KG). pTOP-flash and pFOP-flash plasmids were gifts from Dr. Mingzhou Guo (Department of Gastroenterology \& Hepatology, Chinese PLA General Hospital, Beijing, China).

\section{Animal experiments}

Male Balb/c nude mice at 6 week-old were housed under standard conditions and cared for according to the institutional guidelines for animal care. All animal experiments were approved by the Institutional Animal Care and Use Committee (IACUC) of PLA General Hospital. For the tumorigenicity assay, KYSE30 cells were infected with LV-shTIP30 and LV-shNon at MOI 20 and $5 \times 10^{6}$ cells were injected subcutaneously into each mouse ( $\mathrm{n}=6$ mice / group). The mice were monitored over the course of the experiment and euthanized for histopathology examination at day 28 after cells inoculation. The tumors volume was calculated according to the formula: $\mathrm{V}=$ length $\times$ width $2 \times 0.5$. For experimental metastasis assay, each experimental group (shTIP30 and shNon) consisted of 5 mice. Briefly, $1 \times 106$ cells were injected intravenously through the tail vein into each mouse. After 8 weeks, the mice were euthanized, the presence of tumor nodules was macroscopically determined and the number of tumor nodules formed on the lung/liver surfaces was counted. The lungs and livers were excised and embedded in paraffin for histopathology examination. For the spontaneous metastasis assay, KYSE150 cells were infected with LV-TIP30 and LV-Non at MOI 20 and $5 \times 10^{6}$ cells were injected subcutaneously into each mouse ( $n=6$ mice / group). After 8 weeks, mice were euthanized and examined for development of pulmonary metastasis under microscope.

\section{Patient samples and Immunohistochemical staining}

A total of 93 tissue specimens, including 8 cases of normal mucosa and 85 cases of ESCC, used in MSP analysis were acquired from the Pathology Department of the Medical College of Shantou University (Shantou, P.R.China), collected from 2007 to 2009. This study was approved by the ethical committee of the Tumor Hospital of Shantou University Medical College. The tissue specimens used in IHC staining had been removed from 137 patients with ESCC who had undergone surgery at The 150 hospital of Chinese PLA (Luoyang, Henan, P.R.China) between 2001 and 2005. Patient consent and approval from the 150 Hospital of Chinese PLA Ethics Committee was obtained in order in advance for research purposes. Cancer sample was taken from the tumor tissue where there was no hemorrhage or putrescence, whereas the matched normal mucosa was taken from the surgical cutting edge, which was approximately $3-5 \mathrm{~cm}$ away from the cancerous lesion. The expression of TIP30, $\beta$-catenin and E-cadherin proteins in the specimens was detected with an immunohistochemistry assay. Details of Immunohistochemistry were described previously [17].

Evaluation of immunostaining was independently conducted by 2 experienced pathologists. The expression of TIP30 was scored according to the signal intensity and distribution, details described previously [18]. Tissues with immunohistochemical scoring $\leq 4$ were considered as low expression and with scoring 5-12 as high expression. The expression of TIP30 was evaluated according to the percentage of stained nuclei, independently of intensity. Positive staining was defined as $20 \%$ or greater nucleic staining of the population of cells examined [37]. E-cadherin expression was scored as either normal (junctional) or aberrant, as previously described. Aberrant staining was defined as either negative staining or less than $70 \%$ membranous staining of the population of cells examined. Normal staining was defined as $70 \%$ or greater membranous staining of the study population [38].

\section{Statistic Analysis}

The analyses were carried out using SPSS 16.0 for Windows software (Chicago, IL). $P$-values for dichotomous variables were two-tailed and based on the Pearson chi-square test or the Pearson chi-square test with continuity correction. Continuous variables were analyzed with a Student's t test. Survival curves were calculated using Kaplan-Meier method, and analysis was carried out with the log-rank test. Patient follow-ups were completed on March 15, 2011. The median follow-up period was 41 months (range, 1-93 months). Univariate and multivariate analyses were based on the Cox proportional hazards regression model. Data were presented as the mean \pm 
SEM. A value of $P<0.05$ was considered statistically significant.

\section{Grant support}

This work is supported in part by grants from National Nature Science Foundation of China (81301781, 81330061 and 81402539), Ministry of Science and Technology of China, the Chinese High-Tech Research and Development Program (863 and 973 Project), the Special Project for Infection Disease and New Drug Development, Shanghai Commission of Science and Technology, Shanghai Municipal Education Commission for Shanghai Leading Academic Project (B905).

\section{Abbreviations}

ESCC, esophageal squamous cell carcinoma; QRT-PCR, quantitative reverse-transcription polymerase chain reaction; shRNA, short-hairpin RNA; EMT, epithelial-mesenchymal transition; MSP: MethylationSpecific PCR; BGS: bisulfite genomic sequencing; IF: Immunofluorescence; DAPI, 4',6-diamidino-2phenylindol; IHC: Immunohistochemical; OS, overall survival.

\section{Competing interest statement}

No potential conflicts of interest were disclosed.

\section{List of accession number for a publicly accessible, recognized data repository}

TIP30, Homo sapiens HIV-1 Tat interactive protein 2, 30kDa (HTATIP2), NCBI Reference Sequence: NM_001098520.

\section{REFERENCES}

1. Bandla, S., A. Pennathur, J.D. Luketich, D.G. Beer, L. Lin, A.J. Bass, T.E. Godfrey and V.R. Litle, Comparative genomics of esophageal adenocarcinoma and squamous cell carcinoma. Ann Thorac Surg, 2012. 93(4): p. 1101-6.

2. Hiyama, T., M. Yoshihara, S. Tanaka and K. Chayama, Genetic polymorphisms and esophageal cancer risk. Int J Cancer, 2007. 121(8): p. 1643-58.

3. Yang, J. and R.A. Weinberg, Epithelial-mesenchymal transition: at the crossroads of development and tumor metastasis. Dev Cell, 2008. 14(6): p. 818-29.

4. Thiery, J.P. and J.P. Sleeman, Complex networks orchestrate epithelial-mesenchymal transitions. Nat Rev Mol Cell Biol, 2006. 7(2): p. 131-42.

5. Hawinkels, L.J., H.W. Verspaget, W. van Duijn, J.M. van der Zon, K. Zuidwijk, F.J. Kubben, J.H. Verheijen, D.W. Hommes, C.B. Lamers and C.F. Sier, Tissue level, activation and cellular localisation of TGF-betal and association with survival in gastric cancer patients. Br J Cancer, 2007. 97(3): p. 398-404.

6. Langenskiold, M., L. Holmdahl, P. Falk, E. Angenete and M.L. Ivarsson, Increased TGF-beta 1 protein expression in patients with advanced colorectal cancer. J Surg Oncol, 2008. 97(5): p. 409-15.

7. von Rahden, B.H., H.J. Stein, M. Feith, F. Puhringer, J. Theisen, J.R. Siewert and M. Sarbia, Overexpression of TGF-beta1 in esophageal (Barrett's) adenocarcinoma is associated with advanced stage of disease and poor prognosis. Mol Carcinog, 2006. 45(10): p. 786-94.

8. Gholamin, M., O. Moaven, B. Memar, M. Farshchian, H. Naseh, R. Malekzadeh, M. Sotoudeh, M.T. RajabiMashhadi, M.N. Forghani, F. Farrokhi and M.R. Abbaszadegan, Overexpression and interactions of interleukin-10, transforming growth factor beta, and vascular endothelial growth factor in esophageal squamous cell carcinoma. World J Surg, 2009. 33(7): p. 1439-45.

9. Lopez-Novoa, J.M. and M.A. Nieto, Inflammation and EMT: an alliance towards organ fibrosis and cancer progression. EMBO Mol Med, 2009. 1(6-7): p. 303-14.

10. Vincent, T., E.P. Neve, J.R. Johnson, A. Kukalev, F. Rojo, J. Albanell, K. Pietras, I. Virtanen, L. Philipson, P.L. Leopold, R.G. Crystal, A.G. de Herreros, et al., A SNAIL1SMAD3/4 transcriptional repressor complex promotes TGF-beta mediated epithelial-mesenchymal transition. Nat Cell Biol, 2009. 11(8): p. 943-50.

11. Zhang, L., F. Zhou, Y. Drabsch, R. Gao, B.E. SnaarJagalska, C. Mickanin, H. Huang, K.A. Sheppard, J.A. Porter, C.X. Lu and P. ten Dijke, USP4 is regulated by AKT phosphorylation and directly deubiquitylates TGF-beta type I receptor. Nat Cell Biol, 2012. 14(7): p. 717-26.

12. Zhang, Y.E., Non-Smad pathways in TGF-beta signaling. Cell Res, 2009. 19(1): p. 128-39.

13. Shtivelman, E., A link between metastasis and resistance to apoptosis of variant small cell lung carcinoma. Oncogene, 1997. 14(18): p. 2167-73.

14. Ito, M., C. Jiang, K. Krumm, X. Zhang, J. Pecha, J. Zhao, Y. Guo, R.G. Roeder and H. Xiao, TIP30 deficiency increases susceptibility to tumorigenesis. Cancer Res, 2003. 63(24): p. 8763-7.

15. Lu, B., Y. Ma, G. Wu, X. Tong, H. Guo, A. Liang, W. Cong, C. Liu, H. Wang, M. Wu, J. Zhao and Y. Guo, Methylation of Tip30 promoter is associated with poor prognosis in human hepatocellular carcinoma. Clin Cancer Res, 2008. 14(22): p. 7405-12.

16. Zhao, J., H. Ni, Y. Ma, L. Dong, J. Dai, F. Zhao, X. Yan, B. Lu, H. Xu and Y. Guo, TIP30/CC3 expression in breast carcinoma: relation to metastasis, clinicopathologic parameters, and P53 expression. Hum Pathol, 2007. 38(2): p. 293-8. 
17. Tong, X., K. Li, Z. Luo, B. Lu, X. Liu, T. Wang, M. Pang, B. Liang, M. Tan, M. Wu, J. Zhao and Y. Guo, Decreased TIP30 expression promotes tumor metastasis in lung cancer. Am J Pathol, 2009. 174(5): p. 1931-9.

18. Guo, S., W. Jing, X. Hu, X. Zhou, L. Liu, M. Zhu, F. Yin, R. Chen, J. Zhao and Y. Guo, Decreased TIP30 expression predicts poor prognosis in pancreatic cancer patients. Int $\mathrm{J}$ Cancer, 2014. 134(6): p. 1369-78.

19. Zhu, M., F. Yin, X. Fan, W. Jing, R. Chen, L. Liu, L. Zhang, Y. Liu, Y. Liang, F. Bu, X. Tong, H. Zheng, et al., Decreased TIP30 promotes Snail-mediated epithelialmesenchymal transition and tumor-initiating properties in hepatocellular carcinoma. Oncogene, 2014.

20. Zhao, J., B. Lu, H. Xu, X. Tong, G. Wu, X. Zhang, A. Liang, W. Cong, J. Dai, H. Wang, M. Wu and Y. Guo, Thirty-kilodalton Tat-interacting protein suppresses tumor metastasis by inhibition of osteopontin transcription in human hepatocellular carcinoma. Hepatology, 2008. 48(1): p. 265-75.

21. Ye, Q.H., L.X. Qin, M. Forgues, P. He, J.W. Kim, A.C. Peng, R. Simon, Y. Li, A.I. Robles, Y. Chen, Z.C. Ma, Z.Q. $\mathrm{Wu}$, et al., Predicting hepatitis B virus-positive metastatic hepatocellular carcinomas using gene expression profiling and supervised machine learning. Nat Med, 2003. 9(4): p. 416-23.

22. Micalizzi, D.S., K.L. Christensen, P. Jedlicka, R.D. Coletta, A.E. Baron, J.C. Harrell, K.B. Horwitz, D. Billheimer, K.A. Heichman, A.L. Welm, W.P. Schiemann and H.L. Ford, The Six1 homeoprotein induces human mammary carcinoma cells to undergo epithelial-mesenchymal transition and metastasis in mice through increasing TGFbeta signaling. J Clin Invest, 2009. 119(9): p. 2678-90.

23. Zhao, L., W. Li, W. Zang, Z. Liu, X. Xu, H. Yu, Q. Yang and J. Jia, JMJD2B promotes epithelial-mesenchymal transition by cooperating with beta-catenin and enhances gastric cancer metastasis. Clin Cancer Res, 2013. 19(23): p. 6419-29.

24. Sanchez-Tillo, E., O. de Barrios, L. Siles, M. Cuatrecasas, A. Castells and A. Postigo, beta-catenin/TCF4 complex induces the epithelial-to-mesenchymal transition (EMT)activator ZEB1 to regulate tumor invasiveness. Proc Natl Acad Sci U S A, 2011. 108(48): p. 19204-9.

25. Zhang, C., A. Li, X. Zhang and H. Xiao, A novel TIP30 protein complex regulates EGF receptor signaling and endocytic degradation. J Biol Chem, 2011. 286(11): p. 9373-81.

26. Li, A., C. Zhang, S. Gao, F. Chen, C. Yang, R. Luo and H. Xiao, TIP30 loss enhances cytoplasmic and nuclear EGFR signaling and promotes lung adenocarcinogenesis in mice. Oncogene, 2012.

27. Zhang, W., H.C. Sun, W.Q. Wang, Q.B. Zhang, P.Y. Zhuang, Y.Q. Xiong, X.D. Zhu, H.X. Xu, L.Q. Kong, W.Z. Wu, L. Wang, T.Q. Song, et al., Sorafenib down-regulates expression of HTATIP2 to promote invasiveness and metastasis of orthotopic hepatocellular carcinoma tumors in mice. Gastroenterology, 2012. 143(6): p. 1641-1649 e5.

28. Zhang, Q., L. Chen, B.T. Helfand, T.L. Jang, V. Sharma, J. Kozlowski, T.M. Kuzel, L.J. Zhu, X.J. Yang, B. Javonovic, Y. Guo, S. Lonning, et al., TGF-beta regulates DNA methyltransferase expression in prostate cancer, correlates with aggressive capabilities, and predicts disease recurrence. PLoS One, 2011. 6(9): p. e25168.

29. Bechtel, W., S. McGoohan, E.M. Zeisberg, G.A. Muller, H. Kalbacher, D.J. Salant, C.A. Muller, R. Kalluri and M. Zeisberg, Methylation determines fibroblast activation and fibrogenesis in the kidney. Nat Med, 2010. 16(5): p. 544-50.

30. You, H., W. Ding and C.B. Rountree, Epigenetic regulation of cancer stem cell marker CD133 by transforming growth factor-beta. Hepatology, 2010. 51(5): p. 1635-44.

31. Robertson, K.D., DNA methylation, methyltransferases, and cancer. Oncogene, 2001. 20(24): p. 3139-55.

32. Ikushima, H. and K. Miyazono, TGFbeta signalling: a complex web in cancer progression. Nat Rev Cancer, 2010. 10(6): p. 415-24.

33. Massague, J., TGFbeta in Cancer. Cell, 2008. 134(2): p. 215-30.

34. Adorno, M., M. Cordenonsi, M. Montagner, S. Dupont, C. Wong, B. Hann, A. Solari, S. Bobisse, M.B. Rondina, V. Guzzardo, A.R. Parenti, A. Rosato, et al., A Mutant-p53/ Smad complex opposes p63 to empower TGFbeta-induced metastasis. Cell, 2009. 137(1): p. 87-98.

35. Smith, A.P., A. Verrecchia, G. Faga, M. Doni, D. Perna, F. Martinato, E. Guccione and B. Amati, A positive role for Myc in TGFbeta-induced Snail transcription and epithelialto-mesenchymal transition. Oncogene, 2009. 28(3): p. 42230.

36. Tao, Q., L.J. Swinnen, J. Yang, G. Srivastava, K.D. Robertson and R.F. Ambinder, Methylation status of the Epstein-Barr virus major latent promoter $\mathrm{C}$ in iatrogenic $\mathrm{B}$ cell lymphoproliferative disease. Application of PCR-based analysis. Am J Pathol, 1999. 155(2): p. 619-25.

37. Urakami, S., H. Shiina, H. Enokida, T. Kawakami, T. Tokizane, T. Ogishima, Y. Tanaka, L.C. Li, L.A. RibeiroFilho, M. Terashima, N. Kikuno, H. Adachi, et al., Epigenetic inactivation of Wnt inhibitory factor-1 plays an important role in bladder cancer through aberrant canonical Wnt/beta-catenin signaling pathway. Clin Cancer Res, 2006. 12(2): p. 383-91.

38. Montserrat, N., A. Gallardo, D. Escuin, L. Catasus, J. Prat, F.J. Gutierrez-Avigno, G. Peiro, A. Barnadas and E. Lerma, Repression of E-cadherin by SNAIL, ZEB1, and TWIST in invasive ductal carcinomas of the breast: a cooperative effort? Hum Pathol, 2011. 42(1): p. 103-10. 